\title{
Despatologizar a las subjetividades trans, educar en la diversidad: una deuda de la psiquiatría
}

\author{
Silvia Di Segni ${ }^{1}$
}

1. Doctora de la Universidad de Buenos Aires, Médica psiquiatra.

Autora correspondiente: Silvia Di Segni, E-mail: silvia.disegni@gmail.com

\section{Resumen}

Este texto propone recorrer sucintamente el proceso de patologización de la subjetividad trans desde el nacimiento de la Sexología y la lucha de los colectivos militantes en defensa de sus derechos hasta nuestros días. A la psiquiatría le cabe, hoy, la responsabilidad de despatologizar las subjetividades trans; de aprender a través de los desarrollos teóricos y vivenciales que han producido activistas trans y de influir para lograr que la despenalización y la despatologización sean universales y que se produzcan los cambios culturales imprescindibles que habiliten la convivencia en la diversidad.
\end{abstract}

Palabras clave: Patologización - Despatologización - Travestis - Transgénero-Transexuales - Diversidad sexual.

\section{DEPATHOLOGIZE TRANS SUBJECTIVITIES, EDUCATE IN DIVERSITY. A DEBT OF PSYCHIATRY}

\section{Abstract}

This article proposes to succinctly go through the process of pathologization of trans subjectivity from the birth of Sexology and the struggle of militant groups in defense of their rights to the present day. Today, psychiatry is responsible for depathologizing trans subjectivities; to learn through the theoretical and experiential developments that have produced trans activists and to influence to make decriminalization and depathologization universal and that the essential cultural changes that enable coexistence in diversity occur.

Key words: Pathologization - Depathologization - Transvestites - Transgender-Transsexuals - Sexual diversity. 


\section{La Sexología patologizadora}

Somos traidoras del patriarcado y muchas veces pagamos esto con nuestra vida.

\section{Lohana Berkins}

El nacimiento de la sexología, como rama de la psiquiatría, no fue un evento feliz al servicio del placer y/o de la salud sexual, sino la instalación de un dispositivo de patologización de toda aquella conducta sexual y/o identidad de género que no contemplara la heterosexualidad con fines reproductivos y que no sostuviera el binomio varón/mujer, sin ambigüedad alguna, en tanto éste fundamento del orden patriarcal. De hecho, la sexología se preocupó, básicamente, por las "desviaciones" de los varones dado que las mismas podían afectar el estereotipo que se quería sostener: Varón-Blanco-Endosex-Cis-Heterosexual-Cristiano-Normal-Proveedor, mientras que el otro término del binomio, la mujer, sería desconsiderada, incluso, en las nuevas patologías.

La nueva disciplina entró en tensión con los colectivos de lesbianas y gay que luchaban por sus derechos contra un orden jurídico que lxs penalizaba y que tuvieron que redoblar la lucha cuando el orden psiquiátrico lxs patologizó. Con el tiempo esos colectivos irían incluyendo a Lesbianas, Gay, Bisexuales, Travestis, Transgénero, Transexuales, Intertersexuales, Queer y más (LGBTIQ+). Hasta el día de hoy no se ha logrado igualdad de derechos de todxs ellxs con la heterosexualidad; y, demasiado a menudo, del mismo modo que ocurre con los feminicidios, los miembros de esos colectivos son objeto de abusos que, no pocas veces, terminan con sus vidas y que se han tipificado como travesticidios.

El primer colectivo LG, el Comité Científico Humanitario, fue creado en 1897 por el médico, sexólogo y abogado Magnus Hirschfeld, quien propuso el término travesti para nombrar a quienes deseaban vestir ropas que habían sido rígidamente designadas para el otro de los únicos dos géneros posibles. Es interesante tener en cuenta, para conocer el contexto cultural, que actores y actrices que hicieran papeles del "otro" sexo/género fueron mal vistos y, en general sería mal vista, la actividad teatral en su conjunto por habilitar esa posibiidad. Esto ocurría a fines del siglo XIX, ¿podremos esperar que haya cambiado la manera de pensar el travestismo? El Diccionario de la Lengua de la Real Academia Española (RAE) lo define, hoy en día, del siguiente modo: De travesti e-ismo. $1 . \mathrm{m}$. Práctica que consiste en el uso de las prendas de vestir del sexo contrario. 2. m. Práctica consistente en la ocultación de la verdadera apariencia de alguien o algo. U. t. en sent. fig. (28). En estas dos breves definiciones se despliega un mundo de prejuicios. Se sostiene, allí, que sólo existen dos sexos, claramente definidos, negándose la existencia de personas intersexuales; se confunde sexo con género, dado que las ropas que se usen refieren al género, no al sexo; se oponen los dos únicos sexos reconocidos como "contrarios" - ¿por qué lo serían?- se identifica la "verdadera apariencia" con el sexo asignado al nacer y no con la percepción que la persona tenga de sí misma; se ataca la libertad de cada persona de manifestarse según su deseo tildándolo de "ocultación". Esto último deja en claro el problema que crea el travestismo para el control social: toda persona deberá vestirse de acuerdo a lo que la sociedad disponga de manera de poder identificarla rápida y claramente. Si la persona no vivencia aquello que se le exige, eso no importa, su apariencia verdadera será la que la sociedad patriarcal disponga. Creo que queda bastante claro cuánto ha penetrado en nuestra cultura lo que la psiquiatría patologizó y el trabajo que tenemos por delante para terminar de despatologizar y aportar al desarrollo de una convivencia en la diversidad.

En 1886, Richard von Krafft Ebing publica su libro Psychopathia sexuales, el texto fundacional de la patologización, que tuvo una enorme influencia sobre la psiquiatría y el psicoanálisis, por lo menos, hasta mediados del siglo XX. En él, las conductas que habían sido primero pecado y luego delitos, ahora se convertirían en perversiones. Dos acotaciones sobre este hecho: 1) El fundador de la disciplina había sido Heinrich Kaan quien en 1844 publicó la primera Psychopathia sexualis (Krafft Ebing usará el mismo título), en la que medicalizaba los pecados, pero su obra quedó en el olvido (18).

2) El texto de Krafft Ebing surgió dentro de la cultura europea e influiría en América sobre aquellos sectores que serían educados en la cultura hegemónica, pero, en la misma época en que nacía la sexología, pueblos originarios de América reconocían más de dos géneros y habilitaban el uso de ropas de manera diversa, aquello que Europa llamaría travestismo. Esto ocurría, por ejemplo, en el pueblo tehuelche/mapuche de la Patagonia argentina, por entonces casi exterminado y sobrevive, hasta hoy, en las muxhes de Juchitán, México. La naciente nación argentina de fines del siglo XIX realizaba la Campaña al Desierto (un supuesto desierto, en realidad habitado por pueblos originarios) por medio de la cual combatía a muerte a sus habitantes y se apropiaba de sus tierras. Pero, al obvio rédito económico de esa campaña quizás habría que agregarle un elemento de orden cultural. Esos pueblos también reconocían a las mujeres derechos que criollos y españoles no hubieran aceptado de ningún modo, por lo que su presencia también afectaba la supervivencia del patriarcado importado de Europa. Ese patriarcado que se reforzaría con la sexología de Krafft Ebing y al que la activista Lohana Berkins, en el siglo XX, reconocería como el enemigo principal.

Es necesario dejar en claro que la patologización de la homosexualidad podía tener algún efecto "positivo" dado el marco legal de la época en Alemania. El art. 175 del Código Penal Prusiano consideraba delito a la homosexualidad, fundamentalmente la masculina, dentro de la que se incluía el travestismo y, al patologizarla, se podía sustraer a la persona del ámbito de la justicia. Con ese fin había batallado contra el art. 175 Karl Marie Benkert, quien escribió una carta al Ministro de Justicia 
prusiano exigiendo su derogación. Lo hacía argumentando que era una condición innata y que, por lo tanto, no podía ser penalizada. Dado que uno de los términos más utilizados por entonces, sodomía, remitía claramente al pecado creó uno nuevo, homosexualidad, para expresar la condición que algunas personas tenían y sobre la cual no eran responsables y no podían ser perseguidas por ello. También Krafft Ebing se opuso al art. 175 al considerar que no se podía criminalizar a alguien que consideraba enfermo. Pero la patologización no tuvo el efecto esperado. Por un lado, tal como lo señala Michel Foucault en su texto Los anormales, lejos de mejorar la vida de lxs homosexuales serviría para empoderar a la Sexología sacándole una cuota de poder a la Justicia a través del mecanismo de duplicar al/a la criminal (que seguiría siendo delincuente pero también perversx), al crimen (homosexualidad como delito y como perversión) y al juez (miembro de la justicia y psiquiatra) (13). Por otra parte, el art. 175 no sólo siguió vigente en Alemania sino que, cuando cayó en manos de los nazis fue utilizado para enviar homosexuales a campos de concentración de donde nunca regresaron. Luego de la segunda guerra mundial hubo modificaciones en su contenido, pero sólo pudo ser derogado totalmente en 1994.

Cuando se habla de travestismo se suele hablar de biovarones $^{1}$ con ropas femeninas. Es necesario aclarar que siempre hubo travestismo masculino y femenino y que el femenino tuvo representantes exitosos. Hemos conocido y seguimos conociendo ejemplos invisibilizados de biomujeres que vivieron como varones (hoy las llamaríamos transgénero), como el que recogía la revista Caras y Caretas en 1930 (12). Se trataba de un varón trans que había logrado vivir así 23 años y conseguir lo que nunca hubiera logrado como mujer en esa época: un cargo en un ministerio. Para lograrlo Raquel Suárez se había transformado en Raúl Suárez.

¿En qué contexto surge el texto de Krafft Ebing? En una Alemania claramente influida por la moral protestante que sostenía que no era necesario que hubiera monjas y monjes sino que cada ser humano debía ser monje, autocontrolarse en todo sentido con el fin de no dilapidar ni energía, ni dinero, ni emociones, ni semen. Tal como lo expresara Max Weber, estos principios muy difíciles de respetar, llevaban a desarrollar una forma de vida hipócrita pero, también, eran funcionales al capitalismo en crecimiento ya que permitieron enriquecer a una burguesía que no cesaba de trabajar y evitaba cualquier "desperdicio". En ese marco, tal como se analizó anteriormente (8), desde el siglo XVIII, surgieron cruzadas tendientes a atacar la sexualidad. Una gran campaña fue realizada por el renombrado higienista suizo, Samuel Tissot, quien la dirigió contra la masturbación a través de su libro El onanismo. Disertación sobre las enfermedades producidas por la masturbación, de 1760 (32). Tissot tenía un antecesor a quien no reconocía como tal: un médico y escritor de pornografía británico, el doctor John Marten. Con fines obviamente económicos Marten publicó un folleto en el que amenazaba a quienes se masturbaran con deterioro intelectual, físico, gonorrea, epilepsia, infertilidad, locura y cualquier otro mal de etiología desconocida en su época, 1712. La medicina aprendía de la todavía vigente caza de brujas y, con ese tipo de cruzadas, obtenía un éxito que le permitía vender pócimas destinadas a la supuesta curación. El objetivo de esta campaña fueron los adolescentes, sobre todo varones, que con la creación de las escuelas secundarias adquirirían autonomía en relación a sus padres. Cuando Tissot, una autoridad médica, toma la posta, la charlatanería de origen hace un giro de 180 grados y logra imponer dispositivos de control sobre los jóvenes con el fin de "cuidarlos". El giro se completa cuando se invita al "científico" a llevar sus "conocimientos" a la Encyclopédie de Diderot y D’Alambert bajo el ítem Manstupratio. Todavía entrado el siglo XIX eran frecuentes los suicidios de jóvenes ante la incapacidad de controlarse y el terror a sus consecuencias. Este es un claro ejemplo de como las cruzadas en el ámbito de la sexualidad son fáciles de instaurar, sobre todo cuando hacen pie en preceptos y prácticas religiosas, y muy difíciles de eliminar aún con la ESI (Educación Sexual Integral) mediante. Y que, también es responsabilidad de nuestra disciplina tomar cartas en el asunto.

Si la masturbación era considerada un desperdicio de energía y del fluido fundamental, el semen, la sexualidad también lo sería, excepto que generara productos/ hijxs. Y al tema energético/económico se sumaba la cuestión degenerativa introducida por Morel, de manera que era necesario definir qué conductas era importante erradicar para evitar la degeneración de la especie, en particular de su moral. Si además, con todo esto se contribuía a reforzar el patriarcado la propuesta tenía todos los condimentos para tener éxito. Es interesante acotar que, a fines del siglo XIX, época de comienzo de la obra de Freud, la sociedad vienesa era más liberal respecto de las prácticas sexuales, en comparación con la rigidez de la alemana, aunque mantuviera el puritanismo en las apariencias.

En ese contexto, el sexólogo ubica a su texto en un lugar imprescindible: "Como el mantenimiento de las buenas costumbres y la moralidad es una de las condiciones de existencia más importante para la comunidad pública, el Estado no puede nunca hacer demasiado cuando se trata de proteger a la moralidad en su lucha contra la sensualidad" (19).

Krafft Ebing estaba generando una cruzada y, de allí en más traduciría, como su predecesor Kaan, algunos preceptos religiosos a lenguaje seudocientífico. Por ejemplo: en el siglo IV Juan Crisóstomo, uno de los Padres de la Iglesia Católica, estableció la "natural sumisión" de la mujer al varón como castigo por el pecado de Eva. Catorce siglos después el sexólogo dirá: " $L a$ sumisión voluntaria de la mujer al otro sexo es un fenómeno fisiológico" (19). 
También naturalizaba el masoquismo en la mujer y, obviamente, el sadismo en el varón.

Allí donde había estado Dios ahora se ubicaría a la diosa Naturaleza a través de su hija Fisiología sin que nadie reparara en la contradicción de considerar que un fenómeno fisiológico fuera voluntario. Traducir preceptos religiosos a lenguaje seudocientífico lleva a que estos resuenen masivamente, fácil y rápidamente, algo para lo cual ciertos conceptos científicos tienen dificultad. Se estaba gestando un best seller y se logró ese objetivo. El texto sería publicado ininterrumpidamente, desde 1886 hasta 1903, en varios idiomas y seguiría influyendo de manera directa e indirecta sobre libros de texto de psiquiatría durante todo el siglo XX, así como sobre clasificaciones como el Manual Diagnóstico y estadístico de los trastornos mentales (DSM) de la American Psychiatric Association y la Clasificación Internacional de Enfermedades (CIE) de la Organización Mundial de la Salud (OMS).

¿Qué otros elementos contribuyeron al éxito del texto de Krafft Ebing? Tomó el título de Kaan en latín, lo que generaría una fachada de "autoridad" académica que la naciente sexología todavía no había adquirido. A diferencia de su predecesor que lo había escrito todo en lengua clásica, el sexólogo dejaría algunos pasajes sin traducir al alemán y lo justificaría diciendo que, de ese modo, protegía las mentes sensibles y frágiles que no accedían a ese conocimiento: mujeres y niñxs. Otro aspecto interesante es que el autor casi no recogía experiencia clínica, porque no la tenía; lo que tenía a disposición eran expedientes policiales, material que, como sabemos, produce enorme curiosidad. Sobre el libro actuó la censura para "proteger" a la población. Se habilitó la compra, exclusivamente, a médicos y abogados (varones, obviamente) lo que disparó las ventas.

El texto tiene un subtítulo: "Con especial referencia a la inversión sexual" y, de hecho, la mitad está dedicada a la homosexualidad, básicamente masculina dado que al patriarcado le preocupaba entender por qué un varón renunciaría a la sexualidad y/o a las características de género más valoradas en su entorno. El lesbianismo quedaba en un lugar secundario por diversos motivos: formaba parte del imaginario erótico patriarcal, no producía temidos embarazos y, eventualmente, provocaría menos celos a un hombre que una infidelidad con otro varón.

El terror a la homosexualidad llevaba a detectar precozmente sus "signos". Así el sexólogo se ocuparía de delinear a los varoncitos "afeminados", creando una clara construcción de género dentro de un texto "científico" (9): "El varón ama pasar tiempo con las niñas, jugando a las muñecas, ayudando a su madre en las tareas domésticas; ama la cocina, la costura, bordar, muestra placer en elegir vestimentas femeninas, de tal manera que podría dar consejo a sus hermanas. Más grande, no ama fumar, beber, dedicarse a deportes viriles; encuentra, por el contrario, placer en las telas, las joyas, las artes, las novelas, etc., para lo que muestra ingenio" (19).
Y también describía a las niñas "virilizadas": "El lugar que ella prefiere es el patio donde juegan los varones; trata de competir con ellos en sus juegos. La pequeña no quiere saber nada con las muñecas, su pasión es el caballito de madera, jugar a los soldados y a los bandidos. Muestra desagrado por las tareas femeninas y una enorme torpeza. Se muestra desarreglada, ama los modales rudos y masculinos. En vez de las artes, su gusto y su inclinación la llevan a las ciencias. En ocasiones hace un esfuerzo para beber y fumar. Odia los perfumes y los dulces" (19).

Está claro que en el caso de los varones ya aparece insinuado el travestismo en su amor por las prendas femeninas y que un Varón Guerrero, ideal de la época, no amaría la literatura ni el arte y jamás ayudaría a su madre en las tareas del hogar. Aparentemente el deseo de fumar y beber estaría determinado por la Naturaleza, la misma que también haría que las mujeres amaran las tareas domésticas, nunca fueran torpes $\mathrm{y}$, menos aún, científicas. El absurdo llega al punto de suponer que el amor a los perfumes y dulces definen la femineidad. Estas descripciones, claramente no científicas, suenan ridículas hoy con mucho feminismo corrido bajo los puentes, pero han tenido enorme influencia, y la siguen teniendo, cuando la publicidad sigue construyendo géneros hegemónicos.

Este camino de seudoconocimientos ha bloqueado la emergencia de conocimientos válidos no sólo en la sexología sino también en otros campos de la ciencia, como la biología. La bióloga Anne Fausto Sterling dejó sentado la influencia socio-histórica cultural sobre aquello que considerábamos "natural": "Una de las tesis principales de este libro es que etiquetar a alguien como varón o mujer es una decisión social. El conocimiento científico puede asistirnos en esta decisión, pero sólo nuestra concepción del género, y no la ciencia, puede definir nuestro sexo. Es más, nuestra concepción del género afecta al conocimiento sobre el sexo producido por los científicos en primera instancia" (10).

Esta tesis permite abrir otra mirada sobre la biología dejando en claro cuanto hubo de prejuicio, determinados por la concepciones de género y traducidas a "conocimientos científicos" incluso en las neurociencias en temas como las diferencias entre cerebros "femeninos" y "masculinos". Así como la sexología construyó géneros y una única sexualidad "normal", la medicina construyó los sexos sobre un Lecho de Procusto que recortaba (incluso textualmente) todo aquello que no respondiera a lo que los sexos/géneros preestablecidos requerían para sostenerse.

\section{El travestismo}

El travestismo era, para Krafft Ebing, un claro signo de patología. En su texto aparece una larga referencia a un artículo que encuentra en una revista berlinesa, la National Zeitung, de febrero de 1881, en el que se hace referencia a un "Baile de los misóginos" (19). Reseñaba ese artículo la costumbre berlinesa de organizar reuniones de diversos grupos de varones: gordos, calvos, sol- 
teros, viudos. En este caso se trataba de los "enemigos del sexo femenino" que anunciaban un baile con un afiche en el que se leía: "Gran baile de disfraz vienés". La venta de las entradas se hacía con un control riguroso para evitar problemas. ¿Y qué se encontraba allí? El autor del artículo logró ser invitado y, al entrar, le llamó la atención una bella dama con vestido rosa y una pequeña barba rubia, apenas disimulada por el maquillaje, que pasaba fumando un cigarro y lanzando bocanadas como un coracero. La dama se detuvo a conversar con un "ángel" que también fumaba (algo impensable para una mujer). A Krafft Ebing le llamaron la atención sus voces masculinas y su tema de conversación, hablaban de tabaco. ¡Oh, sorpresa! ¡Eran varones vestidos de mujeres!, lo que sería una muestra de un mundo extraño en el que se mezclaban barbas y aros, rostros maquillados, cigarros y vestidos. Es interesante que el autor del artículo llamara a esa fiesta "Baile de los misóginos" y no "Baile de travestis". Pero se había encontrado allí con personas que conocía, burgueses como él, por lo tanto, tenía que cubrirles las espaldas al consideralos personas que manifestaban su rechazo a las mujeres y no su deseo de ser como ellas. El uso de términos menos peyorativos para sectores medios y altos es común hasta hoy, dado que siempre la discriminación está dirigida esencialmente hacia los sectores de menores recursos. Travesti será el término utilizado en nuestros días para biovarones que ejercen la prostitución con ropas femeninas. Si un biovarón de sector económico alto se traviste será considerado alguien que "juega", y su conducta será llamada, elegantemente, cross dresser.

Lo que a Krafft Ebing le preocupaba de ese baile de supuestos misóginos era la presencia de prostitución masculina que consideraba que debía ser combatida con energía por la policía de Berlín porque: "Siempre la prostitución masculina es mucho más peligrosa para la sociedad que la prostitución femenina: es la mayor de las vergüenzas de la historia de la humanidad" (19).

Es interesante mencionar, en relación a la prostitución y en particular al travestismo, que siempre se criminalizó/patologizó a quien ejercía la prostitución, nunca al prostituyente. Y en el caso del travestismo, resulta difícil entender, dentro de las perversiones, que se considera anormal a quien la practica, pero no se considera anormal al varón que completa la pareja al tener sexo con una persona travesti. Parece bastante obvio que, o las dos partes conforman la patología, o ninguna lo hace.

\section{Otras voces, las propias voces}

Podría pensarse que no hubo otras voces en el campo de la sexología en la época de Krafft Ebing, pero no fue así. A pesar de que la moral protestante influía, y mucho, en Gran Bretaña en la época de la Reina Victoria, en 1901 Henry Havelock Ellis publicó su libro Sexual inversion con una amplitud de miras inesperada para la época (17). Consideraba que tanto la homosexualidad masculina y femenina, como la bisexualidad, debían considerarse normales lo que habría una brecha en el rígido esquema imperante. Si bien su pensamiento fue recogido por Freud, no tuvo la misma influencia ni perdurabilidad que el texto alemán. Todo pensamiento que atentara contra la construcción de binomios rígidamente establecidos: varón/mujer; salud/enfermedad, mente/ cuerpo, aparecía como temible y debía ser atacado o ignorado. Binomios que no sólo contraponen términos sino que construyen diferencias desigualadas, en términos de Ana María Fernández (11). Diferencias que, desde el momento en que se instituyen, uno de sus términos resulta valorado o más valorado. Para sostener esos binomios resulta imprescindible eliminar toda ambigüedad, sea que se manifieste en cuerpos intersexuales que deberán ser operados quirúrgicamente o en las subjetividades trans y no binaries porque no responden a la "o" que debe separar a varones/mujeres sino que, eventualmente, se reconocen como varones " $y$ " mujeres.

La ambigüedad no siempre fue rechazada. Fue valorada, por ejemplo, por Simone de Beauvoir en su texto Hacia una moral de la ambigüedad adonde afirma: "Para alcanzar su verdad, el hombre no debe procurar disipar la ambigüedad de su ser, sino por el contrario, aceptar realizarla: sólo vuelve a encontrarse en la medida en que consiente permanecer a distancia de sí mismo" (7).

Reconocerse en la ambigüedad permite encontrarse, al mismo tiempo que se toma distancia de sí, algo que el psicoanálisis no sólo conoce sino que propone como dispositivo de conocimiento. Sin embargo, aún dentro del psicoanálisis la ambigüedad fue combatida. Un autor del valor de José Bleger escribió, en 1967, Simbiosis y ambigüedad, un texto en el que describía la personalidad ambigua y los aspectos ambiguos de la personalidad como remanentes de una organización primitiva indiferenciada que sólo podía producir patología mientras que la organización madura estaría perfectamente diferenciada (5). Otro ejemplo de la lucha contra la ambigüedad está dirigido a lxs, tan atacadxs, adolescentes. La teoría de los duelos adolescentes que propusieron Arminda Aberastury y Mauricio Knobel en los años '60 del siglo XX sostenía inevitable superar la bisexualidad (ambigüedad) sexual, como etapa imprescindible, para acceder a la madurez (1).

En los últimos años hemos accedido a testimonios y teorizaciones de primera mano, realizadas por personas travestis, trans y no binaries. Esto significa, tener la posibilidad de conocer desde quien lo ha vivido, el dolor de ser atacadx o expulsadx de sus familias tempranamente o de las escuelas, de caer en la prostitución por necesidad o por trata, del acortamiento de la expectativa de vida por la falta de cuidados médicos o por el uso de hormonas de baja calidad, de la constante exposición a la violencia, de la inaccesibilidad a la educación, a la salud y al trabajo, obviamente, todo ello con mucha mayor repercusión en sectores sociales de bajos recursos. Es decisivo, para una buena práctica clínica por parte de quienes son personas cis, escuchar de primera mano estas voces, lo que significa no adjudicarse una autori- 
dad que no se tiene. Para reflexionar sobre ello es saludable acudir a una selección de textos argentinos como los testimonios y análisis de Mauro Cabral y Lohana Berkins en Sexualidades migrantes. Género y transgénero (compilado por Diana Maffia) (20), los testimonios, análisis y propuestas recogidas por Ana Lía Glas y Silvia Kurlat en Diversidades en primera persona. Hacia un imaginario inclusivo en donde se puede encontrar un excelente análisis de situación de Alba Rueda, actualmente Subsecretaria de Políticas de Diversidad de la Nación en el Ministerio de las Mujeres, Género y Diversidad; en lo relativo a la despatologización de la intersexualidad (16), Interdicciones. Escrituras de la Intersexualidad en Castellano (editor Mauro Cabral) (6); sobre las infancias trans, Crianzas. Historias para crecer en toda la diversidad, de Susy Shock (30); con un claro título winnicottiano, Travesti. Una teoría lo suficientemente buena, de Marlene Wayar (33); como un sólido aporte al género no binarie Soy Sabrina soy Santiago. Género fluido y nuevas identidades, de SaSa Testa (29); y, también, la muy reciente novela de vida/ficción de Camila Sosa Villada, Las malas (31). Esta es, solamente, una mínima selección de un gran material a disposición para formarse en el tema a través de quienes están autorizadxs. A la misma se puede agregar un excelente video creado por un colectivo uruguayo, Ovejas negras, que muestra como, sin mala intención médica, pero con prejuicios y sin escuchar a quien consulta, se puede tener conductas iatrogénicas en relación con la población LGBTIQ+. Su título es: ¿Cuál es la diferencia? (26).

\section{Colectivos en lucha}

Sabemos que un paso importante en el camino de la despatologización fue el enfrentamiento con la American Psychiatric Association (APA) y su DSM a partir de los sucesos ocurrido en el bar Stonewall Inn en los que gay, lesbianas y trans se defendieron de una razzia policial. Eso ocurrió en 1969, por lo que se está a poco más de 50 años de esos hechos, pero no parece haberse avanzado lo suficiente. Si bien la homosexualidad desapareció del DSM ese proceso dio cuenta de la enorme presión que hubo para que no ocurriera, para defender lo instituido por el patriarcado. Las luchas contra la APA comenzaron poco después de esos sucesos y lograron que la edición del DSM-II, de 1974, anunciara la eliminación de la homosexualidad. Para ello la APA había apelado, por única vez, al voto de todxs lxs psiquiatras que la conformaban. Aún así, el proceso se completó apenas en 1986. Más tiempo le llevó a la OMS para eliminarla de su CIE ya que lo hizo recién en 1992.

En los relatos de los acontecimientos sucedidos en el Stonewall Inn una versión dice que fueron los gay quienes comenzaron a defenderse, otra dice que fueron las lesbianas y otra, pone a Marsha P. Johnson, activista trans, al frente. Esta manera de relatar los acontecimientos sigue un orden claramente determinado por el rol social. Johnson quien resultó casi invisibilizada en ese evento sería, en los años '80, una líder fundamental en la lucha contra el SIDA a través de ACT UP (Coalición del SIDA para Desatar el Poder y, también, "Pórtate mal"). El colectivo confeccionó afiches y organizó manifestaciones para conseguir una legislación favorable, medicamentos y atención médica. Hizo una manifestación histórica, en 1987, frente al Correo Central de Nueva York el día, muy concurrido, en el que se enviaban las declaraciones de impuestos. Johnson resultó ser una persona incómoda para el poder; en 1992, fue encontrada muerta en el río Hudson, cerca del Stonewall Inn.

Si la despatologización de la homosexualidad siguió un camino sinuoso, el diagnóstico de travestismo continúa hasta hoy haciendo lo mismo. Las luchas de los colectivos trans comenzaron en 1970 en los EE. UU. En ese año se reunieron diferentes colectivos: TransvestiteTransexual Action Organization (TACO), Street Transvestite Action Revolution (STAR), Cokettes, Fems against sexism, Transvestites and Transexuals (TAT) y Radical Queens (RQ), los cuales, en 1971, publicaron un manifiesto en el Boletín de Liberación Trans con el título: "Por la liberación de travestidos y transexuales". En él exigían:

1. La abolición de todas las leyes y todas las restricciones en contra del uso de ropas o adornos sexuados.

2. El fin de la explotación y la discriminación dentro del mundo gay.

3. El fin de las prácticas de explotación por parte de doctores y médicos en los ámbitos del travestismo y de la transexualidad.

4. El tratamiento hormonal gratuito y cirugía a petición.

5. La creación de centros de asistencia para transexuales en todas las ciudades con más de un millón de habitantes, dirigidos por transexuales intervenidos quirúrgicamente.

6. Derechos plenos a todos los niveles de la sociedad y participación plena en las luchas por la liberación de todos los grupos oprimidos.

7. La libertad inmediata para todas aquellas personas que están en manicomios o en prisiones a causa del travestismo o la transexualidad.

Se agregaba que deberían tener derecho a la documentación requerida (21).

Llama la atención que las exigencias fueran dirigidas no sólo a la población cis heterosexual sino también a los varones gay para que cesara su explotación y, no poco importante, a lxs médicxs que explotaban sus necesidades de hormonas y/o cirugía y a lxs psiquiatras que les internaban en manicomios.

Es imprescindible señalar que casi todo lo solicitado fue contemplado por nuestra Ley de Identidad de Género, ley 26.743/2012 vigente en la República Argentina, sin duda, la más progresista que se haya producido, aprobada más de 40 años después de estos reclamos. Un aspecto central de dicha ley fue la definición de la identidad de género: "Se entiende por identidad de género a la vivencia interna e individual del género tal como cada persona la siente, la cual puede corresponder o no con el sexo asignado al momento del nacimiento, incluyendo la vivencia perso- 
nal del cuerpo. Esto puede involucrar la modificación de la apariencia o la función corporal a través de medios farmacológicos, quirúrgicos o de otra índole, siempre que ello sea libremente escogido. También incluye otras expresiones de género, como la vestimenta, el modo de hablar y los modales" (22).

De este modo empodera a les quienes desean realizar una transición, o la han realizado, y quita poder a la psiquiatría cuyos profesionales eran quienes habilitaban, o no, a realizar el proceso. También es necesario mencionar el paso que dio nuestra Ley Nacional de Salud Mental 26.657/2010 cuando dice, en su Capítulo II artículo 3: "En ningún caso puede hacerse diagnóstico en el campo de la salud mental sobre la base exclusiva de: [...] c) Elección o identidad sexual (23).

Estas leyes se adelantaron a lo que sostienen aun las grandes clasificaciones que responden a a la American Psychiatric Association y a la OMS.

\section{Las grandes clasificaciones}

Comparemos las Perversiones sexuales que describía Krafft Ebing con las Desviaciones sexuales de la primera edición del Manual Diagnóstico y estadístico de los trastornos mentales (DSM) de 1952, que se incluyen en la categoría Trastornos de la Personalidad y en la subcategoría
Trastorno de Personalidad Antisocial (2). Resulta claro que no sólo se patologizaba, sino que se creaban las bases para la criminalización. La Masturbación aparecería mencionada dentro de la Reacción adaptativa en la infancia, como un Trastorno del hábito, junto con comerse las uñas o la enuresis.

Hemos mencionado en otras oportunidades (8) que estos listados reúnen conductas claramente abusivas y criminales, como todas aquellas que no cuentan con consentimiento, junto a otras que pueden ser consentidas, que eventualmente afectan solamente a quienes la realizan. El travestismo ocupa un lugar especial: ¿a quién afecta? Es una conducta claramente inocua, excepto para una sociedad que no tolere que se trasgredan sus normas patriarcales. ¿Es ese el motivo por el que se la mezcla con las otras prácticas? O bien se intenta banalizar las más graves o bien se busca criminalizar al travestismo. En cualquiera de los dos casos no hay argumento científico sino mero prejuicio. Los Trastornos Parafílicos podrían desaparecer sin mayor problema toda vez que las conductas delictivas pasaran al ámbito de la justicia y las no delictivas quedaran estrictamente en el ámbito privado sin intromisión de la psiquiatría.

Comparemos las Perversiones de Krafft Ebing con las Desviaciones sexuales del primer DSM casi 70 años después:

\begin{tabular}{c|c}
$\begin{array}{c}\text { Perversiones sexuales, } \\
\text { Krafft Ebing, 1886 }\end{array}$ & $\begin{array}{c}\text { Desviaciones sexuales, } \\
\text { DSM, 1952 (000-x63) }\end{array}$ \\
\hline Inversión sexual & Homosexualidad \\
\hline Fetichismo & Petichismo \\
\hline Pedofilia & Travestismo \\
\hline Travestismo & Escoptofilia \\
\hline Voyeurismo & Sadismo Masoquismo \\
\hline Sadomasoquismo & Mutilación sexual \\
\hline Mutilaciones sexuales & Masturbación en la infancia \\
\hline Masturbación & \\
\hline Coprofagia & Exhibicionismo \\
\hline Zoofilia & Violación \\
\hline Incesto & \\
\hline
\end{tabular}

La comparación de estos listados muestra como influyó Krafft Ebing en el DSM que, a su vez, lo continuó haciendo sobre lxs autorxs de libros de texto de psiquiatría para ir confluyendo en el mismo listado. Antes del DSM, cada autor de libro de texto, fundamentalmente varón, hacía su listado sobre la base de Krafft Ebing, pero se permitía agregar otras conductas, lo que podía llevar- nos a encontrar listados de hasta 22 conductas consideradas anormales. Esto también da cuenta que no estábamos en presencia de conocimientos sino de prejuicios.

La edición de 1987 del DSM (3), que finalmente elimina a la Homosexualidad, reemplaza al Travestismo por el Fetichismo travestista y agrega en las Parafilias no especificadas algunas prácticas que también analizaba Krafft 
Ebing como la Zoofilia y la Coprofilia. En ese apartado agregaba también: Escatología telefónica (que subsiste hasta hoy, aunque los teléfonos fijos casi hayan desaparecido), el Parcialismo, la Klismafilia y la Urofilia. Quizás el uso de enemas para excitarse, la Klismafilia, tuviera sentido cuando éstos se utilizaban desde la infancia con frecuencia pero, aunque actualmente subsiste en el DSM, no parecería ser una práctica muy difundida. El Parcialismo, excitación con una parte del cuerpo de la pareja y no con todo el cuerpo o diferentes partes de él, aparece como otra práctica que no afecta a nadie, pero se persigue igual a partir de estereotipar la generación de excitación.

Finalmente, en el DSM 5, de 2013, se modificará la categoría Parafilias por la de Trastornos parafílicos (4). Este cambio, finalmente, despatologizará a las fantasías que no generaran estrés que, a nuestro criterio, era otro resabio religioso dentro de la sexología: así como la religión consideraría pecado tanto a la acción como la intención, se equipararía la acción con la fantasía en el ámbito sexual. En esta edición el orden estadístico cambia, pero las conductas listadas son las mismas:

\section{$302.82($ F65.3)}

Voyeurismo
Exhibicionismo
Froteurismo
Masoquismo sexual
Sadismo sexual
Pedofilia
Fetichismo
Travestismo
Trastorno Parafílico no especificado (3)

Lo que hará el DSM 5 será incluir la Disforia de género que alude a la persona que sufre estrés por no sentirse bien con el género que se le adjudicó al nacer y desear cambiarlo. Si, como es obvio, ese estrés es producto de la discriminación y presión familiar que sufre, eso se invisibiliza y el trastorno recae sobre la víctima, duplicando el daño.

La CIE-10, de 1992, en su novedoso Capítulo V referido a Trastornos mentales y del comportamiento, incluía:

\section{F64 Trastorno de la identidad sexual}

Transexualismo

Travestismo no fetichista (de doble rol)

Trastorno de la identidad sexual en la infancia

Otros trastornos de la identidad sexual

Trastorno de la identidad sexual sin especificación (24)

\section{F65 Trastornos de la inclinación sexual}

\section{Fetichismo}

Travestismo fetichista

Exhibicionismo
Escoptofilia (voyeurismo)

Paidofilia

Sadomasoquismo

Trastornos múltiples de la inclinación sexual

Otros trastornos de la inclinación sexual

Trastorno de la inclinación sexual sin especificación (24)

Es decir que la CIE-10 no incluye la Homosexualidad pero le otorga un lugar especial al Transexualismo y al Travestismo que serán eliminados de la CIE-11 en 2019... al mismo tiempo que se incluya la Discordancia de género (25). Se aclara, en la última edición, que se cambió el concepto de Identidad sexual por Discordancia de género para disminuir la estigmatización. ¿La estigmatización realizada por quiénes? ¿Por lxs médicxs que utilizan la CIE? No parece ser un camino muy fructífero para lograrlo. La discordancia es definida allí como: "Una discordancia marcada y persistente entre la experiencia de género del individuo y el sexo asignado" (25).

Este ítem se asemeja a la Disforia de género del DSM. Siempre está presente el hecho de que la persona sufre por algo que no ha decidido (asignación de sexo/ género), pero se describe esta situación como centrada en quien es víctima de presión/discriminación social y no en la sociedad que le estresa o enferma. Es necesario señalar, de todos modos, que, para algunos colectivos trans habría que mantener estos ítems para permitir el acceso de personas trans a documentación, hormonización y cirugía en países que no lo admiten a simple requerimiento. En ellos, las personas trans que no tengan estrés por su situación deberán simularla para que la psiquiatría habilite lo que es su derecho. Y esto podría ocurrir a sabiendas de ambas partes. Esa trampa ha sido generada por la larga historia de nuestra disciplina en este campo y debe ser desarticulada por nosotrxs mismxs.

Esto significa para los psiquiatras que, en la formación de futuros profesionales a través de nuestras clases o libros de texto, en la difusión de nuestras ideas, en nuestra práctica clínica, debemos hacer particular hincapié tanto en la convivencia en la diversidad (de la que todxs formamos parte pero no todxs con las mismas posibilidades y derechos) como en corrernos del lugar de supuesta palabra autorizada y escuchar las voces realmente autorizadas, en este caso particular de las subjetividades trans, pero esto vale para toda situación relativa a sexo, género, sexualidades, etnia, religión, cultura, sectores sociales, capacidades diferentes, que nos resulten ajenas como ha ocurrido, demasiado tiempo, con las voces de lxs usuarixs de la Salud Mental.

Hoy podemos apreciar como se construía la definición de "normalidad" sexoafectiva (endosex cis heterosexual con fines procreativos) que proponía el influyente texto de Freedman, Kaplan y Sadock en sus ediciones de 1975 (14) y 1976 (15): “Una adaptación sexual sana comprende la capacidad de comprometerse en experiencias sexuales sin miedo o culpa y, en un momento adecuado, enamorarse y casarse con la pareja elegida y mantener el 
sentimiento de amor y de atracción sexual hacia el cónyuge. (La mujer... el hombre...) ambos cónyuges deberían desear niños y tener la capacidad psicológica para colmar estos deseos" (14).

El sostenimiento de esto pilares patriarcales no resulta inocuo ni tiene sustento científico. Ha generado la enorme violencia que subyace tanto a los feminicidios como a toda agresión contra la población LGBTIQ+. Paul B. Preciado ha sintetizado claramente que detrás de lo que se ha llamado "violencia de género" hay toda una construcción de rígidos estereotipos que la producen: "Creo que el género mismo es la violencia, que las normas de masculinidad y feminidad, tal y como las conocemos, producen violencia. Si cambiáramos los modos de educación en la infancia, quizá modificaríamos lo que llamamos violencia de género" (27).

Una última consideración lingüística. Se habla de homo y travestifobia. Sabemos que una fobia es un miedo inmotivado y no hay ningún miedo en quienes ejercen violencia contra la población LGBTIQ+, lo que hay es tanto rechazo como odio. Por eso, propongo reemplazarla por misoqueeria, rechazo/odio hacia toda la población que podríamos reunir en el término queer.

\section{Conflictos de intereses}

La autora declara no tener conflictos de intereses respecto de este artículo.

\section{Referencias bibliográficas}

1. Aberastury A. Knobel M (1986), La adolescencia normal. Buenos Aires: Paidós.

2. American Psychiatric Association (APA) (1952) Diagnostic and Statistical Manual of Mental Disorders (DSM). Washington: APA.

3. American Psychiatric Association (APA) (1987) Diagnostic and Statistical Manual of Mental Disorders (DSM - III - R). Barcelona: Masson.

4. American Psychiatric Association (APA) (2013), Guía de consulta de los diagnósticos del DSM-5, Washington DC: APA.

5. Bleger J. (1967) Simbiosis y ambigüedad. Buenos Aires: Paidós.

6. Cabral M (editor) (2009) Interdicciones. Escrituras de la intersexualidad en castellano. Córdoba, Argentina: Anarrés (En línea: https://brujulaintersexual.org/2016/07/09/libro-interdicciones-escrituras-de-la-intersexualidad-en-castellano-editor-mauro-cabral/).

7. de Beauvoir S. (1956) Hacia una moral de la ambigüedad. Buenos Aires: Schapire.

8. Di Segni S (2013) Sexualidades. Tensiones entre la psiquiatría y los colectivos militantes, Bs. As., FCE.

9. Di Segni; S.; (2013), "Sexología, géneros y heteronormatividad"; http://www.memoria.fahce.unlp.edu.ar/trab_eventos/ev.3458/ev.3458.pdf (consultado el 2/02/2020).

10. Fausto Sterling A (2000) Cuerpos sexuados. Barcelona: Melusina.

11. Fernández AM (2009) "Las diferencias desigualadas: multiplicidades, invenciones políticas y transdisciplina", en Nómada, núm. 30, universidad central colombia. disponible en línea: <http://www.anamfernandez.com.ar/publicaciones/index.html> (consultado el 4/05/2011).

12. Ferro G (2010) Degenerados, anormales y delincuentes. Buenos Aires, Marea.

13. Foucault M (2000) Los anormales. Buenos Aires: FCE.

14. Freedman AM, Kaplan HI, Sadock BJ (1975) Compendio de psiquiatría, Barcelona: Salvat.
15. Freedman AM, Kaplan HI, Sadock BJ (1976) Modern Synopsis of Psichiatry. Comprehensive Textbook of Psychiatry. Baltimore: William and Wilkins.

16. Glas AL, Kurlat S (2014) Diversidades en primera persona. Hacia un imaginario inclusivo. Buenos Aires: Del Dragón.

17. Havelock Ellis H (1912) "Sur la sexualité psychopathique", en Armand Marie (ed.), Traité de psychologie pathologique. París: Alcan.

18. Henrico Kaan, Psychopathia Sexualis. Lipsiae, Apud Leopoldum Voss, 1844. Versión en inglés: Benjamin Kahan, ed. Heinrich Kaan's. Psychopathia Sexualis" (1844): A Classic Text in the History of Sexuality. Melissa Haynes, trans. Ithaca, N.Y.: Cornell University Press, 2017.

19. Krafft-Ebing, Richard von (1895) Psychopathia sexualis avec recherches spéciales sur l'inversion sexuelle. París: Georges Carré.

20. Maffia D (Compil.) (2012) Sexualidades migrantes. Género y transgénero. Buenos Aires: Feminaria editores.

21. Mérida Jiménez RM (2009) Manifiestos gays, lesbianos y queer, Barcelona: Icaria.

22. Ministerio de Justicia y Derechos Humanos. Presidencia de la Nación; (2012), Identidad de género. Ley 26.743. http://servicios.infoleg.gob.ar/infolegInternet /anexos/195000-199999/197860/norma.htm. (consultado el $1 / 02 / 2020)$.

23. Ministerio de Salud de la Nación. Ley Nacional de Salud Mental 26.657. Infoleg: http://servicios.infoleg.gob.ar/infolegInternet/anexos/175000-179999/175977/norma.htm (consultado el 1/2/2020).

24. OMS. (1992) Clasificación Internacional de Enfermedades. Cap. V. OMS: Geneva.

25. OMS (2019), CIE-11 https://icd.who.int/browse11/ l-m/es\#http $\% 3 a \% 2 f \% \quad 2$ 2fid.who.int $\% 2$ ficd $\% 2 f e n t i-$ ty\%2f411470068, (consultado el 1/02/2020).

26. Ovejas Negras (2012) ¿Cuál es la diferencia? (En línea: https://www.youtube.com/ watch? v=WUnGHQNpxQY (consultado el 3/01/2013). 
27. Preciado PB (2010) "La sexualidad es como las lenguas. Todos podemos aprender varias", El país, 13 de junio de 2010, (http://elpais.com/diario /2010/06/13 / eps/1276410414_850215.html (consultado el 24/05/2015).

28. Real Academia Española (2014) Diccionario de la lengua https://dle.rae.es/travestismo? $\mathrm{m}=302$ (consultado el 28/01/2020).

29. SaSa Testa (2018) Soy Sabrina soy Santiago. Género fluido y nuevas identidades. Buenos Aires: Ariel.
30. Shock S (2016). Crianzas. Historias para crecer en toda la diversidad, Buenos Aires: Muchas Nueces.

31. Sosa Villada C (2019) Las malas. Buenos Aires: Grupo Planeta.

32. Tissot S (1760 [2003]) El onanismo. Disertación sobre las enfermedades producidas por la masturbación. Madrid: Asociación Española de Neuropsiquiatría.

33. Wayar M (2018) Travesti. Una teoría lo suficientemente buena. Buenos Aires: Muchas Nueces. 